JRC2009-63025

\title{
IMPROVED TANK CAR DESIGN DEVELOPMENT: ONGOING STUDIES ON SANDWICH STRUCTURES
}

\author{
David Y. Jeong \\ David C. Tyrell \\ Michael E. Carolan \\ A. Benjamin Perlman \\ Volpe National Transportation Systems Center \\ US Department of Transportation \\ Cambridge, Massachusetts, USA
}

\section{ABSTRACT}

The Government and industry have a common interest in improving the safety performance of railroad tank cars carrying hazardous materials. Research is ongoing to develop strategies to maintain the structural integrity of railroad tank cars carrying hazardous materials (hazmat) during collisions.

This paper describes engineering studies on improved tank car concepts. The process used to formulate these concepts is based on a traditional mechanical engineering design approach. This approach includes initially defining the desired performance, developing strategies that are effective in meeting this performance, and developing the tactics for implementing the strategies. The tactics are embodied in the concept. The tactics and concept evolve through engineering design studies, until a design satisfying all of the design requirements is developed. Design requirements include service, manufacturing, maintenance, repair, and inspection requirements, as well as crashworthiness performance requirements.

One of the concepts under development encases the pressurized commodity-carrying tank in a separate carbody. Moreover, this improved tank car concept treats the pressurized commodity-carrying tank as a protected entity. Welded steel sandwich structures are examined as a means to offer protection of the commodity tank against penetrations from impacting objects in the event of a collision. Sandwich structures can provide greater strength than solid plates of equal weight. Protection of the tank is realized through blunting of the impacting object and absorption of the collision energy. Blunting distributes impact loads over a larger area of the tank. Energy absorption reduces the demands on the commodity tank in the event of an impact. In addition, the exterior carbody structure made from sandwich panels is designed to take all of the in-service loads, removing the commodity tank from the load path during normal operations.

Design studies described in this paper focus on the protection aspect of using sandwich structures. Studies are conducted to investigate the influence of different parameters, such as sandwich height and core geometry, on the forcedeformation behavior of sandwich structures. Calculations are carried out numerically using nonlinear finite element analysis. These analyses are used to examine the crashworthiness performance of the conceptual design under generalized impact scenarios.

\section{INTRODUCTION}

Over the past several decades, Government and industry have sponsored research to improve the safety performance of railroad tank cars. However, several recent accidents involving the release of hazardous material (hazmat) have focused attention on the safety performance of railroad tank cars during accidents such as derailments and collisions. Table 1 lists recent railroad hazmat accidents that have been or are being investigated by the National Transportation Safety Board (NTSB) for their probable cause. In some accidents, release of hazardous materials occurred from an impacting object (e.g., broken coupler) penetrating and puncturing the end (or head) or the side (or shell) of the commodity-carrying tank.

Results from industry-sponsored research are applied to develop and implement tank car designs to improve safety performance. An industry research and development effort began in 2006, called the Next-Generation Rail Tank Car (NGRTC) project, specifically for this purpose. Dow Chemical Company, Union Pacific Railroad, and Union Tank Car Company were the industry sponsors of this project. In 2007, the Federal Railroad Administration (FRA) and Transport Canada, two Government regulatory agencies in North 
America, began collaborating with the NGRTC project through Memoranda of Cooperation. Results from Governmentsponsored research are used to support rulemaking [1]. Cooperative activities include full-scale shell impact testing of conventional tank cars. Separate activities include design development.

\section{Table 1: Recent Railroad Hazmat Accidents}

\begin{tabular}{ll} 
Location & Date \\
\hline Minot, North Dakota & January 18, 2002 \\
Macdona, Texas & June 28, 2004 \\
Graniteville, South Carolina & January 6, 2005 \\
Anding, Mississippi & July, 10, 2005 \\
Texarkana, Arkansas & October 15, 2005 \\
New Brighton, Pennsylvania & October 20, 2006 \\
Shepherdsville, Kentucky & January 16, 2007 \\
Oneida, New York & March 12, 2007 \\
\hline
\end{tabular}

The objectives of FRA-sponsored hazmat research are: (1) to understand the load and deformation environment under which tank cars operate during normal operations and during accidents, (2) to understand structural performance of tank cars in the current fleet, (3) to develop alternative designs, operating procedures and technologies for maintaining tank integrity during all scenarios, and (4) to assist the FRA Office of Safety in the promulgation of responsive rules to maintain the safety of hazardous materials transportation by rail. In addition, meetings with the industry are being planned to facilitate stakeholder involvement.

This paper describes FRA-sponsored work in progress on the development of improved crashworthiness tank car designs. Previous work on the improved design development is reviewed, which includes the overall approach in developing an improved design [2] and the preliminary conceptual design developed from that approach [3]. Moreover, this paper examines the evaluation of welded steel sandwich structures as a means to protect the commodity tank against penetrations from impacting objects in the event of a collision.

\section{IMPROVED DESIGN DEVELOPMENT APPROACH}

The Volpe National Transportation Systems Center (Volpe Center) conducts and manages research to support the FRA in its mission to promulgate rail safety regulations. The objective of this research is to maintain the integrity of the commoditycarrying tank under a broad range of loading conditions that vary from the normal operating environment to rare events such as accidents. As a consequence of the recent railroad hazmat accidents, the structural integrity and crashworthiness of railroad tank cars has come under great scrutiny. Moreover, recent research has focused primarily on maintaining tank integrity under accident loading conditions. The framework for improved tank car design development effort was described in previous work [2].
Processes of mechanical engineering design provide the basis of FRA/Volpe Center research to formulate concepts for improved tank car designs. In the present context, mechanical engineering design refers to the utilization of mathematics, material science, and engineering mechanics principles to develop analysis tools that can be used to optimize potential designs for enhanced structural performance. This approach has been used in other railroad applications; specifically in the development of crush zones for passenger equipment [4-6], a state-of-the-art cab car end frame design [7], and improved locomotive crashworthiness features [8].

In the present application for railroad tank cars, this systematic approach entails the following steps: (1) defining the collision conditions of concern, (2) evaluating the structural behavior of conventional tank car designs under these collisions conditions, and (3) developing and evaluating alternative designs that may improve performance. In this context, improvement means increasing the survivable impact speed under accident loading conditions over that of conventional or current tank car designs. Evaluations of the alternative designs are accomplished iteratively.

The approach used in conducting this research is summarized in the flow diagram illustrated in Figure 1 . Moreover, the figure is a schematic representation of the scientific method in which an alternative design is hypothesized to provide improvement over existing designs. Evaluation tools are then used to confirm or refute the hypothesis. In the present work, the evaluation techniques or tools are generally numerical models that have been verified and validated with experimental data.

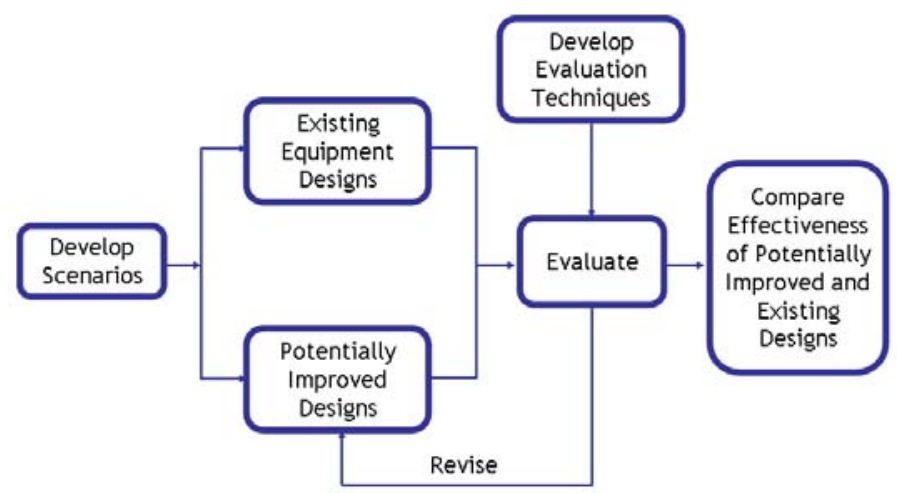

Figure 1: Framework for Improved Tank Car Design Development

\section{Define collision conditions of concern}

Accident scenarios involving hazmat release from tank cars have been developed from review of accidents, and are intended to bound the range of accidents that can lead to release of hazmat from a tank car. For example, each of the accidents listed in Table 1 occurred from either a derailment or a train collision. In addition, studies of accident data, which include the FRA's Railroad Accident/Incident Reporting 
System (RAIRS) [9], indicate that these two types of accidents account for a vast majority (more than 90 percent) of all hazmat-related accidents [10].

Accident data are also collected by the Railroad Tank Car Safety Research and Test Project, which is sponsored by the Railway Supply Institute (RSI) and the Association of American Railroads (AAR). Between 1965 and 2005, a total of 252 tank cars released toxic inhalation hazard (TIH) materials in 176 accidents [11]. Figure 2 shows the distribution of these releases in terms of causes and quantity of released commodity. While less than half of all releases are caused by failures in the head and the shell of pressurized tank cars, such failures account for 85 percent of the total gallons of lost commodity. Failures to valves and fittings account for about one-third of the total accidents-caused releases, but less than 5 percent of the total gallons of lost lading. That is, the frequency of head and shell failures is slightly less than all other causes combined, but their consequence in terms of gallons of lost commodity is much greater.
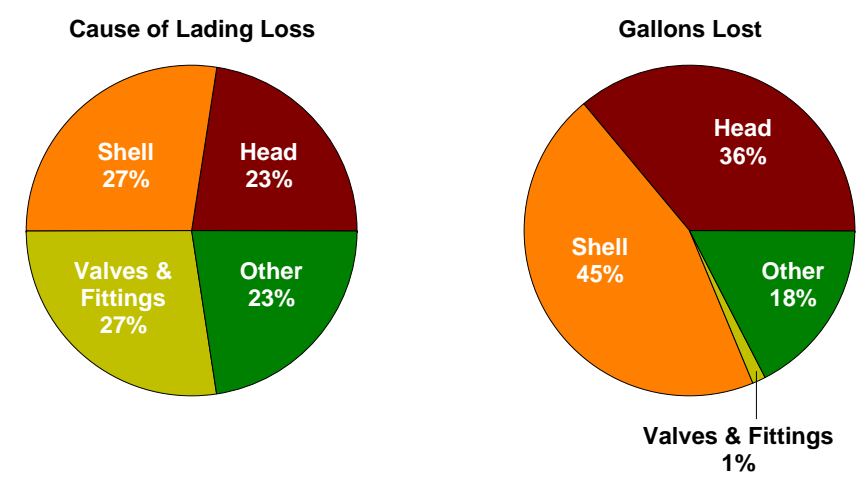

Figure 2: Accident-Caused Releases in TIH Tank Cars, 1965-2005 [11]

Accident history suggests that puncture can occur anywhere on the commodity tank, but punctures are more likely to occur below the beltline and near the ends of the car.

In addition, collision dynamics modeling performed by the Volpe Center [12-13] suggests that the gross motions of rail cars in derailments and collisions produce secondary car-to-car impacts that are similar to those observed in actual accidents when cars come off the rails. Modeling of derailments and collisions as well as field experience suggests that the car-tocar impact scenarios of concern are head and shell impacts.

\section{Evaluate structural behavior of current designs}

Tools have been developed and are under continuous refinement to evaluate different tank car designs. Development and refinement of these tools entail engineering analyses and testing. The analyses must account for the key physical aspects of collisions which include: (1) quantifying forces and deformations as functions of time which define the forcedeformation or force-indentation characteristic, (2) elasticplastic stress-strain behavior with large deformations, (3) fluid- structure interaction, and (4) material failure. For example, detailed finite element analysis modeling of a conventional chlorine tank car under generalized head [14] and shell [15] impacts have been conducted. Full-scale shell impact testing of the conventional chlorine tank car [16] was funded and conducted by the NGRTC project to validate the detailed FEA model. ${ }^{1}$ Moreover, the detailed FEA model was used to simulate the full-scale shell impact test included material failure. The material failure model was based on benchmark testing of unnotched Charpy bars [17].

The essence of these analysis and testing efforts is shown in Figure 3 in which structural behavior under impact loading is described in terms of the force-indentation characteristic. The figure compares the calculated characteristic with that derived from the processed data from the full-scale shell impact test. The test was conducted with a ram car weighing 286,000 lb, striking the side of a conventional chlorine tank car at an impact speed of $15 \mathrm{mph}$, and puncturing the shell. The commodity tank was pressurized to $100 \mathrm{psi}$, and contained fluid lading with 11 percent outage. Based on the impact test data, the energy to puncture, or shaded area under the forceindentation curve corresponding to the test, is about 0.9 million $\mathrm{ft}-\mathrm{lb}$. Energy to puncture is a metric of structural performance that may be used to evaluate different tank car designs.

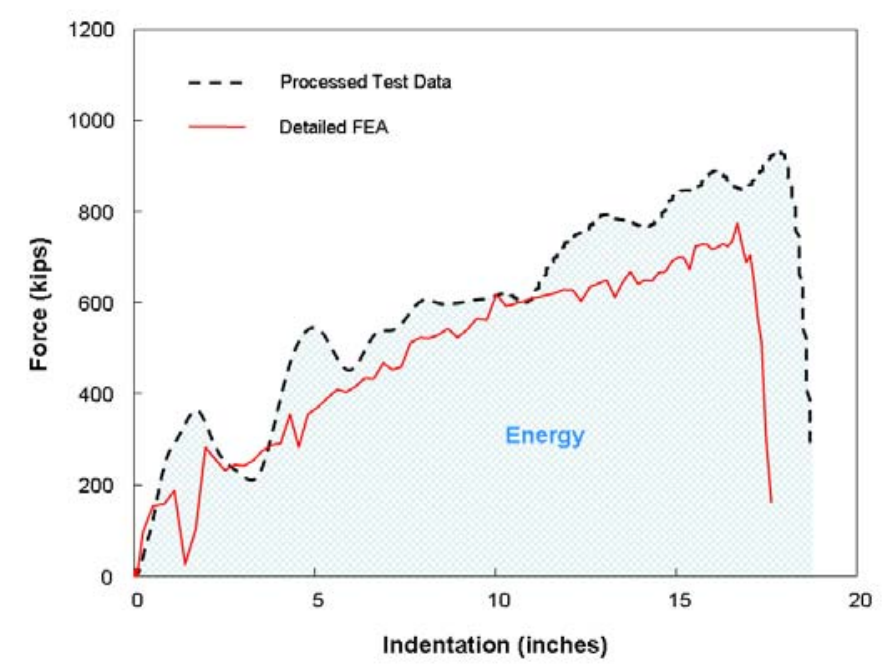

Figure 3: Force-Indentation Characteristics for Full-Scale Shell Impact Test at $15 \mathrm{mph}$

Semi-empirical evaluations of head tests performed in the 1970s indicate that internal pressurization of the commodity tank decreases the velocity at which puncture is expected to occur [18]. Detailed finite element analyses conducted in support of the NGRTC project [19] also suggest that the energy to puncture decreases with increasing internal pressure.

\footnotetext{
${ }^{1}$ FRA coordinated with the Volpe Center to design of the full-scale shell impact tests.
} 


\section{Develop alternative designs}

In the systematic approach adopted for this work, concepts for improved crashworthiness designs are formulated through the following process: (1) defining the desired performance, (2) developing strategies that are effective in meeting this performance, (3) and developing the tactics for implementing the strategies. The tactics and concept are evolved with engineering design studies, until a design satisfying all of the design requirements is developed. Design requirements include service, manufacturing, maintenance, repair, and inspection requirements, as well as crashworthiness performance requirements. In previous work, the desired performance goal was set to improve the impact energy to puncture the commodity tank by a factor of four over the conventional chlorine tank car.

Previous research identified four design functions that can help maintain the structural integrity of the commodity tank during collisions: (1) blunt the impact loads, (2) absorb collision energy, (3) provide a strong foundation for the loadblunting and energy-absorbing features, and (4) control the load path to the commodity tank.

Head shields on current cars principally act to blunt the impact load. In effect, the shield makes the size of the impacting object appear larger, spreading load over a greater area of the commodity tank. By doing so, the energy required to puncture the tank is increased. The addition of an energyabsorbing component can further increase the energy to puncture the tank. In essence, the energy absorption decreases the speed of impact experienced by the commodity tank.

Strengthening the tank allows an energy-absorbing component to crush at a higher load. If the service loadbearing structure is separate from the commodity tank, the tank does not experience cyclic service loads and the potential for failure by fatigue cracking is reduced.

Engineered sandwich structures have the potential to perform some of these functions in the conceptual design. ${ }^{2}$ The primary advantages of sandwich panels over alternative construction materials and technologies are the ability to support loads in the plane of the panel while offering effective energy-absorbing capability in the normal (out-of-plane) direction.

Sandwich panels comprise two face sheets that are separated by a core. A sandwich panel with a square egg-crate core is shown in Figure 4. The egg-crate geometry is used here as an exemplar. A variety of core geometries are available to be used within sandwich structures. The separation of the face sheets by the core increases the moment of inertia of the panel which produces a higher bending stiffness-to-weight ratio than solid plates. The mechanical behavior of sandwich structures depends on the properties of the face sheet and core materials, the configuration of the core, and attachments. The face sheets

\footnotetext{
2 The term engineered is used to emphasize that the structure requires careful design to achieve desired performance levels.
}

and the core of the sandwich structures described in this paper are steel.

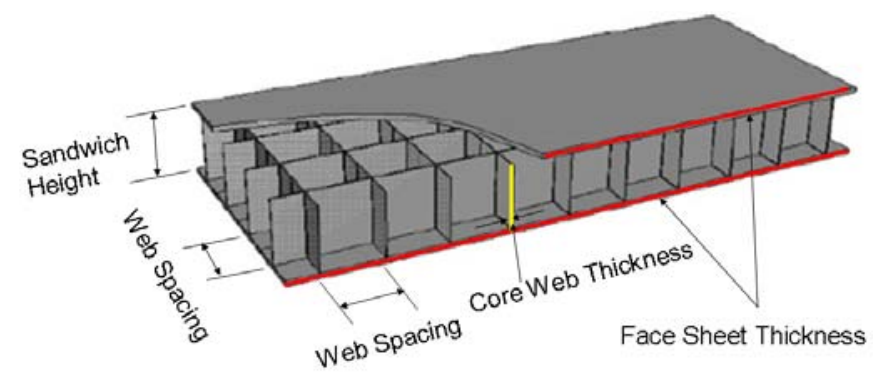

Figure 4: Annotated Egg-Crate Sandwich Panel

\section{PRELIMINARY CONCEPTUAL DESIGN}

A preliminary conceptual design that integrates the four functions was developed and described in previous work [3]. This alternative design treats the conventional tank as a protected entity which is encased by a separate carbody. The conventional tank is reinforced with stiffeners around the head. The reinforced tank with insulation sits within a structural carbody, which is made of sandwich panels. Between the reinforced and insulated tank and the exterior carbody is a structural foam saddle, designed to support the tank while isolating it from service loads from the carbody. Therefore, the construction sequence for this design is a three-phase fabrication process: (1) construction of the reinforced tank, (2) construction of the exterior carbody, and (3) marriage of the reinforced tank and carbody.

Figure 5 shows the various stages of assembly for an alternative design. This illustration differs from that shown in the original [3] in two ways. Here only the ends (head) of the conventional tank are reinforced. The other difference is that the sandwich panels comprising the exterior carbody structure in Figure 5 are curved, whereas flat panels forming an octagonal cross-section were considered in the original concept.

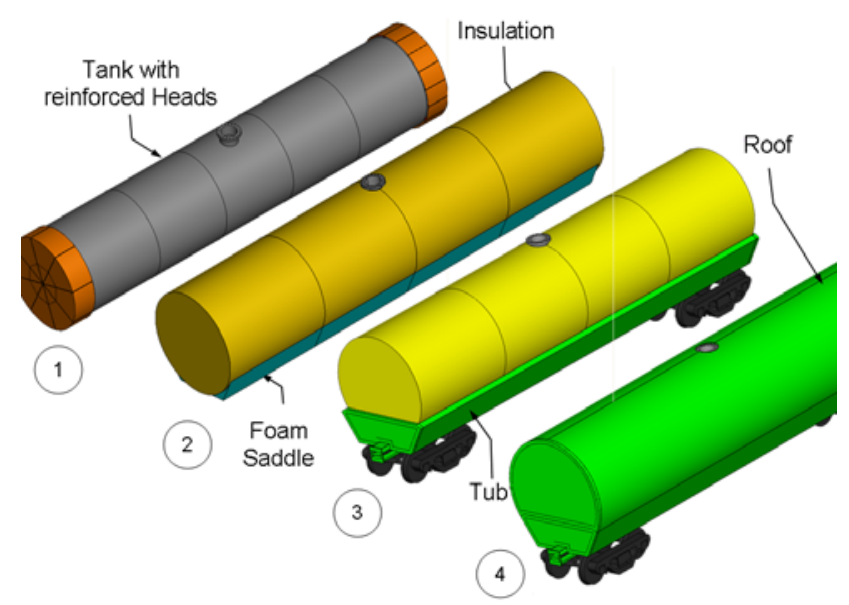

Figure 5: Progression of Conceptual Design Assembly 
The commodity tank is assumed to have a wall thickness of 5/8 inch and a nominal capacity of 17,300 gallons. The entire car, when fully loaded, weighs less than 286,000 lb. With this weight budget, 39,000 lb of material is available for new structure that may be applied for safety enhancements. The extreme width of the exterior carbody is 128 inches. The roof/top of the carbody is about $13^{1 / 2}$ feet above top-of-rail. Moreover, these dimensions are within the clearances of AAR Plate B [20].

Dynamic, nonlinear finite element analyses [21] were used to conduct initial evaluations of the preliminary conceptual design under generalized head and shell impact scenarios at a closing speed of $15 \mathrm{mph}$. In these impact scenarios, a rigid punch was assigned a weight of 286,000 lb. In addition, simplifying assumptions were made in the initial analyses. For example, the commodity tank contained no fluid lading and was unpressurized. Material failure modeling was not included in the analyses. Moreover, sandwich structures were assumed to have a square egg-crate core, and were modeled using a continuum element approximation [22-24]. Under these assumptions, the initial evaluations suggested that the desired performance goal could be attained [3]. Considering the generalized head impact scenario, the improved design was shown to absorb about eight times as much energy as the conventional tank. Considering the generalized shell impact scenario, the improved concept was shown to absorb about 4.5 times as much energy as the conventional tank. More refined evaluations of the preliminary conceptual design are conducted by including additional details, which are described as follows.

\section{DETAILED CONCEPTUAL DESIGN EVALUATION}

The work in progress described in this paper includes studies to examine the effect of sandwich structure details, refined analysis to evaluate the integrated conceptual design, and an assessment of the continuum approach to modeling sandwich structure cores.

\section{Effect of Sandwich Structure Details}

A variety of sandwich structure details can satisfy the allowable weight and space budgets for the alternative design. The influence of selected sandwich structure parameters on the force-indentation characteristic is examined. Flat sandwich panels with square egg-crate cores are assumed. Specifically, the effects of two parameters are studied: core web thickness and sandwich height. The sandwich panels are assumed to be made from TC-128B tank car steel.

Figure 6 shows the effect of varying the core web thickness. In these results, the face sheet thickness is held constant and equal to 0.125 inch. The figure indicates that the force levels increase with increasing core web thickness.

The results shown in Figure 7 suggest that a range of sandwich heights can provide similar performance in terms of the force-indentation characteristic. Face sheet and core thicknesses are varied to maintain a constant sandwich weight per unit area. The figure also shows that the force-indentation characteristic for these three sandwich structures is equivalent to that of a solid plate with a thickness of 1.7 inches.

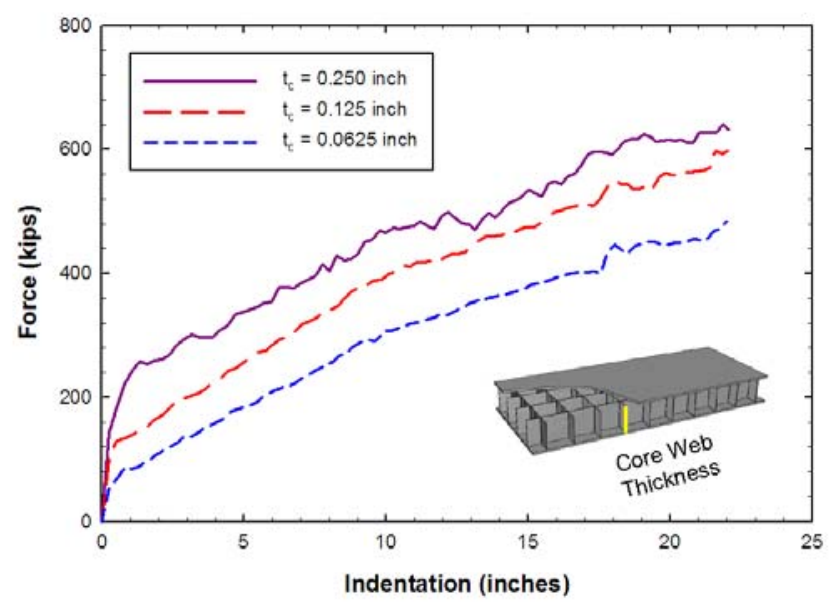

Figure 6: Influence of Core Web Thickness

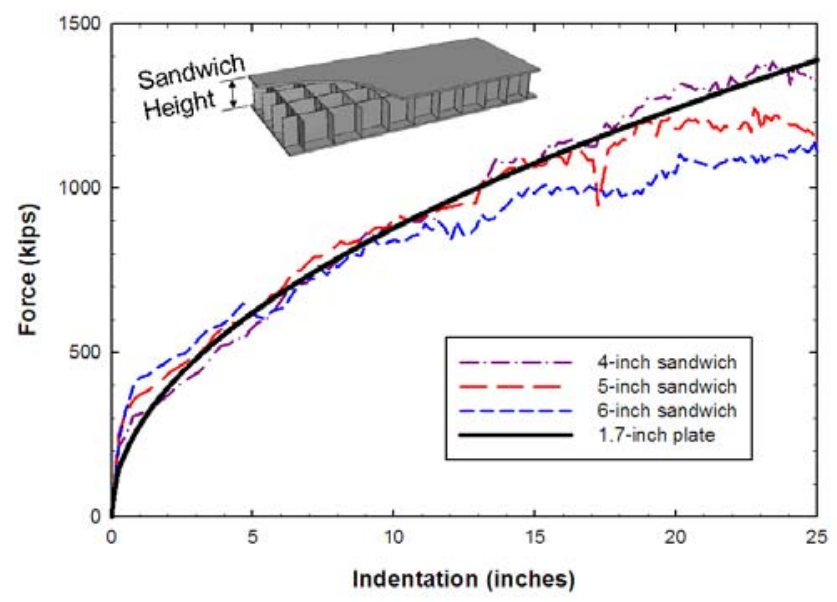

Figure 7: Influence of Sandwich Height

\section{Refined Analysis}

Numerical evaluations of the preliminary conceptual design are refined by including additional details. For example, both the exterior carbody and the commodity tank are included to examine the deformation of these components in the integrated design during a collision. In the initial evaluations [3], the protection to the commodity tank offered by the exterior carbody was modeled by an unconstrained, flat sandwich panel. In the refined analysis, the commodity tank is pressurized but contains no fluid lading. In addition, material failure is not explicitly modeled. Evaluations based on these assumptions provide estimates of the energy absorption demands for the integrated conceptual design.

Figure 8 shows schematic diagrams of the generalized impact scenarios for which the evaluations of the integrated design are performed. In both scenarios, the tank car is impacted by a rigid punch with a 6-inch by 6 -inch face. 


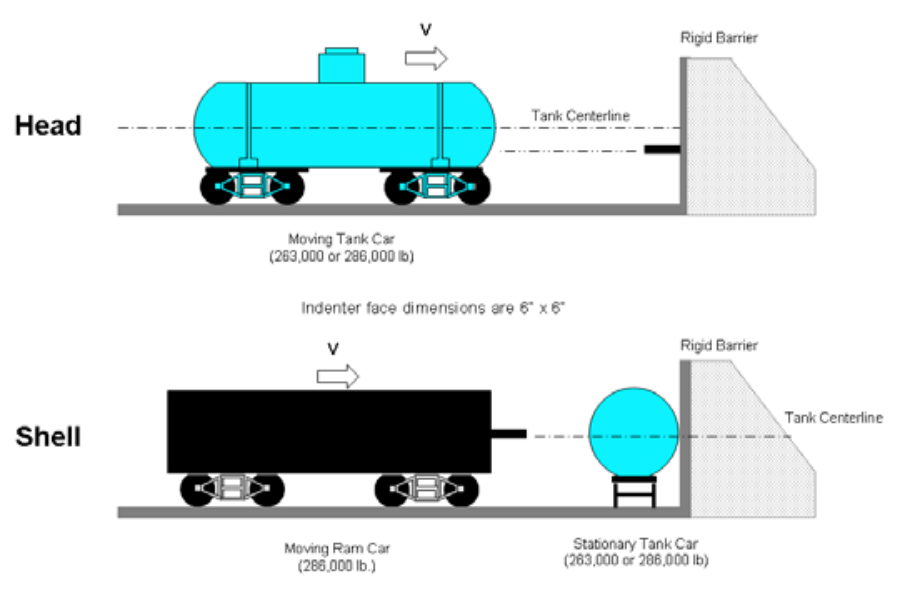

Figure 8: Impact Scenarios for Integrated Design Evaluation

Table 2 summarizes the details of the sandwich structures that make up the exterior carbody, and are assumed in the evaluation of the integrated design. The particular details are annotated in Figure 4.

Table 2: Details for Integrated Design Evaluation

\begin{tabular}{|l|c|c|}
\hline \multirow{2}{*}{ Detail } & \multicolumn{2}{|c|}{ Impact Scenario } \\
\cline { 2 - 3 } & Shell & Head \\
\hline Sandwich Height & 6 inches & 6 inches \\
\hline Core Web Thickness & 0.25 inch & 0.1 inch \\
\hline Face Sheet Thickness & 0.125 inch & 0.25 inch \\
\hline
\end{tabular}

Considering the generalized head impact scenario, the bar graph shown in Figure 9 compares three different energies: (1) the kinetic energy associated with a mass corresponding to 286,000 lb and an impact speed of $30 \mathrm{mph}$ (8.6 million ft-lb), (2) the energy to puncture a conventional chlorine tank (about 1 million ft-lb), and (3) the energy absorbed by different components in the integrated design, the sum of which is equal to the kinetic energy. That is, the kinetic energy is converted into different forms of energy in the integrated design: (1) energy dissipated in plastic deformation of the commodity tank, (2) energy dissipated in plastic deformation of the exterior carbody, (3) energy dissipated by the reinforcements, and (4) work against the internal pressurization which is referred to as fluid work. The figure indicates that most of the energy (over 60 percent) is dissipated in plastically deforming the exterior carbody. Consequently the carbody may be considered as a sacrificial structure. For a given impact scenario, the tank will maintain its integrity if the combined energy absorption capacity of the tank and the sacrificial structure is higher than the kinetic energy. The more kinetic energy that gets absorbed in the sacrificial structure, the less kinetic energy has to be absorbed by the commodity tank. Therefore, in a higher speed impact, the tank will have a greater capacity to absorb kinetic energy than if no sacrificial structure were present.

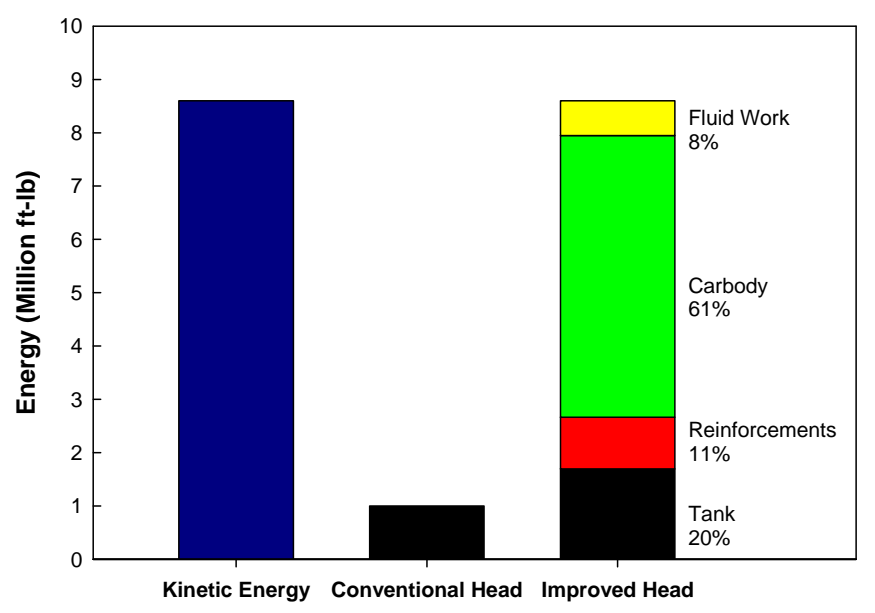

Figure 9: Energy Absorption in Generalized Head Impact

The energy to puncture the conventional chlorine tank car is calculated from finite element analyses that include the effect of fluid-structure interaction by modeling the fluid lading with a Lagrangian mesh [14]. In addition, material failure is included in the analyses by assuming that failure initiates when the effective plastic strain exceeds a critical value for a given state of stress or stress triaxiality [25].

Similarly, Figure 10 compares energies for the generalized shell impact at $25 \mathrm{mph}$. In this impact scenario, the kinetic energy is equal to 6 million $\mathrm{ft}-\mathrm{lb}$, and the energy to puncture the conventional shell is 1.2 million $\mathrm{ft}-\mathrm{lb}$. In the original preliminary conceptual design reported in [3], the commodity tank was reinforced with sandwich panels to provide a strong foundation for the exterior carbody structure to blunt the impact load and absorb collision energy in the event of a shell impact. When the reinforcement is included in the analysis, however, its contribution to the total energy absorption is nearly negligible. Figure 10 shows that without including reinforcements, the sacrificial structure (i.e., exterior carbody) can potentially absorb over 70 percent of the kinetic energy.

Refined evaluations have quantified the energy-absorption demands of the preliminary integrated design. Based on these results, the impact energy to puncture the commodity tank is estimated to be about six to nine times that over the conventional chlorine tank car. In the shell impact scenario, a relatively stiff sandwich structure facilitates energy dissipation over a large volume of the carbody. In the head impact scenario, reinforcements help to activate energy dissipation over a significant volume of the head sandwich as well as the tank. However, success of this stiffening concept relies on the ability of the external structure to effectively blunt the impactor. Localization of stress and deformation restricts the volume of material available to dissipate significant energy. 


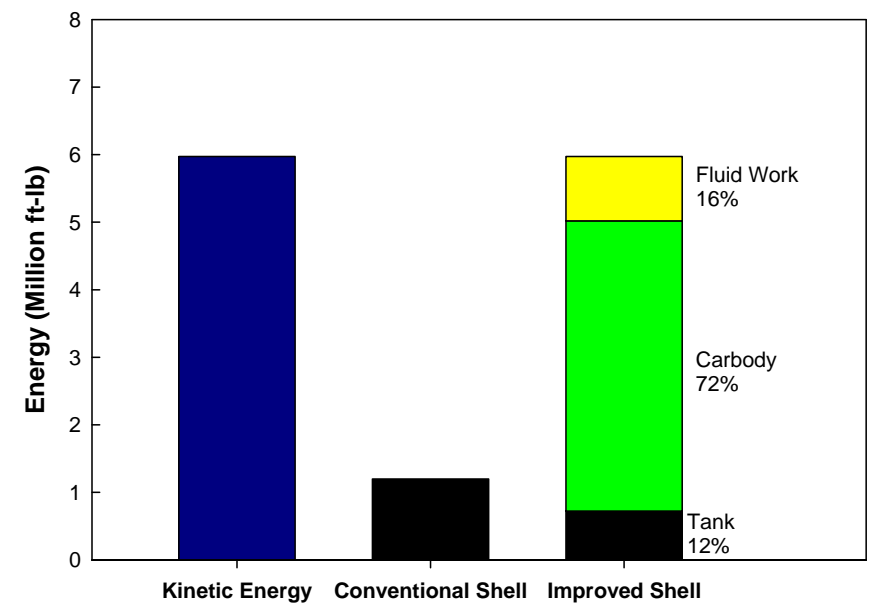

Figure 10: Energy Absorption in Generalized Shell Impact

\section{Discrete Modeling versus Continuum Approach}

Initial evaluations of the preliminary conceptual design reported in [3] and the results presented in this paper are based on the continuum approximation [22-24] of the sandwich core. In order to assess these evaluations, the continuum approach to modeling the core geometry of square egg-crate sandwich panels is examined.

Figure 11 compares the force-indentation characteristic for a flat sandwich panel with a square egg-crate core calculated using the continuum element approach with that calculated from a discrete finite element model. In the continuum model, the core is modeled using two layers of solid elements with properties selected to match the deformation of the square eggcrate geometry in shear and compression [23-24]. In the discrete model, the core is modeled with shell elements. In both models, the face sheets are modeled with shell elements. Referring to Figure 4, these results are based on the following sandwich panel details: 6-inch web spacing, 6-inch sandwich height, 0.25-in face sheet thickness, and 0.125-in core web thickness. In addition, the entire sandwich panel is made from TC-128B tank car steel. Moreover, the force-indentation characteristic provided by the continuum modeling approach for this particular sandwich configuration agrees very closely with that from the discrete model up to about 15 inches of indentation. Consideration is being given to alternative core geometries since determining that the egg-crate core sandwich panel force would start to decrease after 15 inches of displacement in the shell impact. Core geometries which potentially allow greater displacements are currently being evaluated.

The continuum element approach is useful to perform rapid evaluations, but a discrete model of the core appears to be necessary in order to capture local effects and examine failure accurately. Continuum elements are appropriate to model the behavior of sandwich structures at locations sufficiently far away from the point of impact.

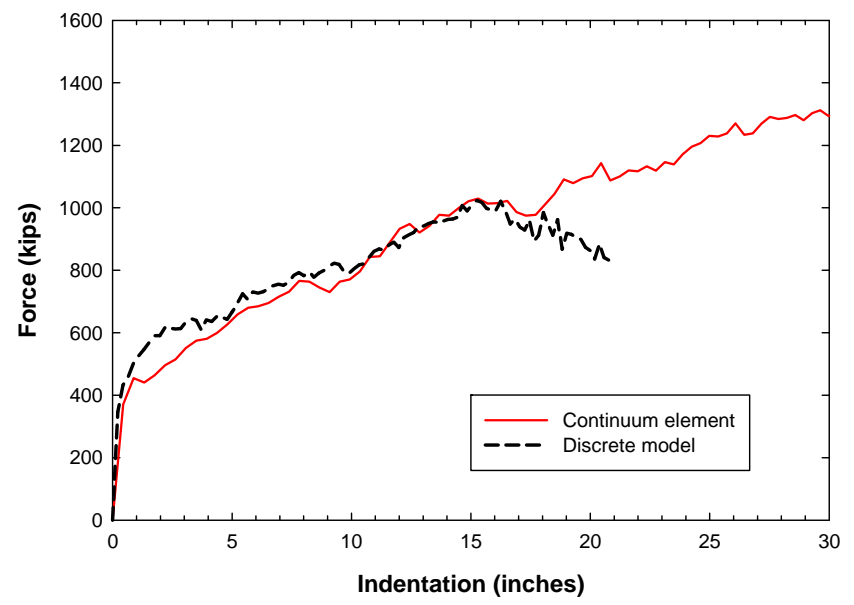

Figure 11: Comparison between continuum approach and discrete model

\section{Fabrication Evaluation}

In principle, it may be desirable for the steels used in the fabrication of sandwich structures to possess high strength. In practice, it is also desirable for such steels to be easily welded and readily formable to create curved shapes when necessary (which implies high ductility). In addition processes to join components together (such as welding and bolting) require study for the present application of sandwich structures.

The FRA has awarded a Phase III Small Business Innovative Research (SBIR) contract to Cellular Materials International, Inc. (CMI) to study the fabrication issues of material selection and joining processes regarding sandwich structures for railroad tank car applications. ${ }^{3}$ Moreover, the primary task for CMI in this work is to build sandwich structure specimens that will be used in severe deformation tests that are discussed in the following section.

\section{DISCUSSION}

Component-level impact tests were conducted on sandwich structures designed to protect a tank head conducted under the NGRTC project. Two types of sandwich structures were tested; one with a foam-core, the other was an engineered metal structure (EMS) with corrugated/pleated core geometry. Neither of these test articles, however, was optimized to maximize structural performance. Consequently, the EMS with corrugated/pleated core appeared to have inferior performance to that of an equivalent solid plate [19]. This behavior was also observed for stiff honeycomb-core panels developed to resist blast loads for ships hulls for the Office of Naval Research [26]. In the naval application, the honeycomb panel is superior to a solid plate when subjected to a planar impulse, but inferior when more localized. By analogy, the EMS with the

\footnotetext{
${ }^{3}$ Phase III refers to the commercialization stage of the SBIR. Phase I and II refer to feasibility assessment and developmental stages of the innovation. CMI examined sandwich panels for naval applications in Phases I and II of the SBIR.
} 
corrugated/pleated core may be superior to an equivalent solid plate in certain impact scenarios (e.g., those involving relatively large indenters), but has been shown to be inferior for impacts with a 6-in by 6-in indenter.

An alternative core for the naval application, called a doubly-corrugated soft core [26], was found to provide superior performance to an equivalent solid plate under planar and localized impulses. Again, by inference, it would appear reasonable that an alternative core (to be determined) may outperform a solid plate over a greater range of indenter sizes for the tank car application.

In analyses conducted in support of the NGRTC project [19], it was estimated that a solid steel plate of about three inches would be required to prevent puncture from a side impact assuming a rigid indenter with a 6-in by 6-in face that weighs 295,000 lb and a closing speed of $25 \mathrm{mph}$. Under the same assumptions, a solid steel plate more than six inches thick would be required to prevent a head impact at a closing speed of $30 \mathrm{mph}$. These equivalent thickness estimates are based on a shear failure criterion originally developed through research sponsored by the industry in the 1970s [18]. In this criterion, the failure mechanism initiating puncture is excessive shear around the perimeter of the indenter. ${ }^{4}$

In the context of design strategies, solid steel plates with increased thickness would provide sufficient load blunting but little energy absorption capability. In addition, increased thickness can lead to a relatively stiff structure that localizes the impact forces, which in turn can lead to localized material failure as opposed to large structural denting.

Generally speaking, sandwich structures are used in applications that require strong bending strength. In the current application, however, protection of the commodity tank against penetration offered by sandwich structures is realized through blunting of impact loads and absorption of the collision energy. Refined evaluations have shown that the energy absorption demands on the sandwich structures in the preliminary integrated design to prevent puncture are challenging. The conversion of kinetic energy into plastic deformation depends on many factors including the magnitude of the impact load, mode of deformation and failure, and material properties. As seen in the naval application, a relatively soft core may be more desirable over a stiffer core in order to enable load blunting and energy absorption more effectively. The complexities in designing sandwich structures are manifested through a competition of failure modes prior to penetration and failure of the commodity tank. These failure modes of the sandwich structure include tearing of the face sheets, crushing or buckling of the core, and shear failure of the core. In the event of a collision, for example, high stress concentrations at the edges of the indenter can cause a large differential in the displacement of the face sheets. Tension in the face sheets makes them vulnerable to tearing or failure in this situation.

\footnotetext{
${ }^{4}$ The shear failure criterion was used to develop semi-empirical equations to predict head punctures [16].
}

Moreover, the specific technical challenge in future work will be to develop a deformable energy-absorbing structure with an equivalent thickness less than three to six inches.

Alternative core geometries to the egg-crate core geometry are shown in Figure 12. Severe deformation tests are being planned to examine load-deformation behavior of these core geometries. The pipe or tubular core has been considered in automobile applications as car bumpers and guardrails [27]. The $\mathrm{X}$-core is similar to the doubly-corrugated core developed for the naval application [26]. The diamond core is a variation of an alternative core considered for the naval application [28]. The severe deformation tests will be used to: (1) rank the different core geometries for structural performance and (2) confirm the modeling of sandwich structures under the prescribed loading conditions.

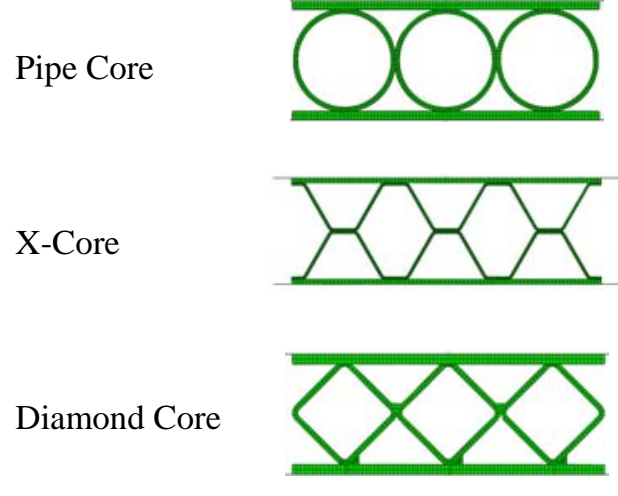

Figure 12: Candidate Core Geometries

Initial results from ongoing analyses suggest that the core arrangements shown in Figure 12 potentially allow greater displacements in the shell impact than the egg-crate core. Some of these analyses results also indicate that the boundary conditions of the panel - the manner in which the panel is supported - significantly influence the performance.

\section{SUMMARY AND NEXT STEPS}

Recent accidents involving the release of hazmat, with consequent fatalities, have focused attention on the structural integrity and crashworthiness of railroad tank cars. Government-sponsored research is ongoing to understand the load-deformation behavior of tank cars during accidents as well as during normal operating conditions. Research will be conducted to understand structural performance of tank cars in the current fleet. A mechanical engineering design approach that relies on the scientific method was reported in previous work, and is being applied to develop alternative designs and technologies to maintain tank integrity in all scenarios. An alternative concept that treats the pressurized commoditycarrying tank as a protected entity has been developed from this approach. Moreover, this alternative concept is being evaluated for structural performance, and is being studied for feasibility in fabrication. Other alternative designs may be considered. 
Ultimately, testing of optimized designs must be conducted to validate the modeling and the feasibility of sandwich structures for railroad applications. Such tests are under development. Component-level tests are being planned to verify the modeling of critical and difficult-to-analyze components. Tank car designs will be refined from results of detailed analysis and testing.

\section{ACKNOWLEDGEMENTS}

The work described in this paper was sponsored by FRA Office of Research and Development. Dr. Thomas Raslear is the Acting Chief of the Equipment and Operating Practices Division. Mr. Francisco Gonzalez is the FRA program manager for research on railroad tank cars.

\section{REFERENCES}

[1] Tyrell, D.C., Jeong, D.Y., Jacobsen, K., Martinez, E., "Improved Tank Car Safety Research," Proceedings of the 2007 ASME Rail Transportation Division Fall Technical Conference, RTDF2007-46013, September 2007.

[2] Tyrell, D.C., Jacobsen, K., Talamini, B., Carolan, M., "Developing Strategies for Maintaining Tank Car Integrity During Train Accidents," Proceedings of the 2007 ASME Rail Transportation Division Fall Technical Conference, RTDF2007-46015, September 2007.

[3] Carolan, M., Talamini, B., Tyrell, D., “Update on Ongoing Tank Car Crashworthiness Research: Predicted Performance and Fabrication Approach,” Proceedings of the 2008 ASME/IEEE Joint Rail Conference, JRC200863052, April 2008.

[4] Tyrell, D., Jacobsen, K., Martinez, E., “A Train-to-Train Impact Test of Crash Energy Management Passenger Rail Equipment: Structural Results,” Proceedings of the 2006 ASME International Mechanical Engineering Congress and Exposition, IMECE2006-13597, November 2006.

[5] Martinez, E., Tyrell, D., Rancatore, R., Stringfellow, R., Amar, G., "A Crush Zone Design for an Existing Passenger Rail Cab Car," Proceedings of the 2005 ASME International Mechanical Engineering Congress and Exposition, IMECE2005-82769, November 2005.

[6] Martinez, E., Tyrell, D., Perlman, A.B., "Development of Crash Energy Management Designs for Existing Passenger Rail Vehicles," Proceedings of the 2004 ASME International Mechanical Engineering Congress and Exposition. IMECE2004-61601, November 2004.

[7] Mayville, R., Stringfellow, R., Johnson, K., Tyrell, D., "Rail Vehicle Car Cab Collision and Corner Post Designs According to APTA S-034 Requirements," Proceedings of the 2003 ASME International Mechanical Engineering Congress, IMECE2003-44114, November 2003.

[8] Tyrell, D., Severson, K., Marquis, B., Martinez, E., Mayville, R., Rancatore, R., Stringfellow, R., Hammond, R., Perlman, A.B., "Locomotive Crashworthiness Design Modifications Study," Proceedings of the 1999 IEEE/ASME Joint Railroad Conference, Institute of
Electrical and Electronics Engineers, Catalog Number 99CH36340, 1999.

[9] Nayak, P.R., Rosenfield, D.B., Hagopian, J.H., “Event Probabilities and Impact Zones for Hazardous Materials Accidents on Railroads,” Final Report, DOT/FRA/ORD83/20, November 1983.

[10] Anderson, R.T., and Barkan, C.P.L., "Railroad Accident Rates for Use in Transportation Risk Analysis," Transportation Research Record 1863 (2004) 88-98.

[11] Treichel, T., "List of Accident-Caused Releases of Toxic Inhalation Hazard (TIH) Materials from Tank Cars, 19652005,” RSI-AAR Railroad Tank Car Safety Research and Test Project Report No. RA 06-05, June 2006.

[12] Paetsch, C.R., Perlman, A.B., Jeong, D.Y., "Dynamic Simulation of Train Derailments," Proceedings of the 2006 ASME International Mechanical Engineering Congress and Exposition, IMECE2006-14607, November 2006.

[13] Jeong, D.Y., Lyons, M.L., Orringer, O., Perlman, A.B., "Equations of Motion for Train Derailments," Proceedings of the 2007 ASME Rail Transportation Division Fall Technical Conference, RTDF2007-46009, September 2007.

[14] Tang, Y.H., Yu, H., Gordon, J.E., Jeong, D.Y., "Finite Element Analyses of Railroad Tank Car Head Impacts," Proceedings of the 2008 ASME Rail Transportation Division Fall Technical Conference, RTDF2008-74022, September 2008.

[15] Tang, Y.H., Yu, H., Gordon, J.E., Jeong, D.Y., Perlman, A.B., "Analysis of Railroad Tank Car Shell Impacts Using Finite Element Method,” Proceedings of the 2008 ASME/IEEE Joint Rail Conference, JRC2008-63014, April 2008.

[16] Tang, Y.H., Yu, H., Gordon, J.E., Priante, M., Jeong, D.Y., Tyrell, D.C., Perlman, A.B., "Analysis of Full-Scale Tank Car Shell Impact Tests," Proceedings of the 2007 ASME Rail Transportation Division Fall Technical Conference, RTDF2007-46010, September 2007.

[17] Yu, H., Jeong, D.Y., Gordon, J.E., Tang, Y.H., "Analysis of Impact Energy to Fracture Unnotched Charpy Specimens Made from Railroad Tank Car Steel," Proceedings of the 2007 ASME Rail Transportation Division Fall Technical Conference, RTDF2007-46038, September 2007.

[18] Shang, J.C., Everett, J.E., "Impact Vulnerability of Tank Car Heads,” Shock and Vibration Bulletin 42 (1972) 197210.

[19] Kirkpatrick, S.W., "Detailed Puncture Analyses of Various Tank Car Designs,” Applied Research Associates, Inc. Draft Final Report, October 2008.

[20] Association of American Railroads, Technical Services Division, Mechanical Section - Manual of Standards and Recommended Practices.

[21] ABAQUS Version 6.7. Providence: Dassault Systèmes, 2007. 
[22] Fleck, N.A., Deshpande, V.S., "Isotropic constitutive models for metallic foams," Journal of the Mechanics and Physics Solids 48, (2000) 1253-1283.

[23] Xue, Z., Hutchinson, J.W., "Preliminary assessment of sandwich plates subject to blast loads," International Journal of Mechanical Sciences 45, (2003) 687-705.

[24] Xue, Z., Hutchinson, J.W., "Constitutive model for quasistatic deformation of metallic sandwich cores," International Journal for Numerical Methods in Engineering 61 (2004) 2205-2238.

[25] Bao, Y., Wierzbicki, T., "On fracture locus in equivalent strain and stress triaxiality space," International Journal for Mechanical Sciences 46 (2004) 81-98.
[26] Wei, Z., Deshpande, V.S., Evans, A.G., Dharmasena, K.P., Queheillalt, D.T., Wadley, H.N.G., Murty, Y.V., Elzey, R.K., Dudt, P., Chen, Y., Knight, D., Kiddy, K., "The resistance of metallic plates to localized impulse," Journal of the Mechanics and Physics of Solids 56 (2008) 20742091.

[27] Alghamdi, A.A.A., "Collapsible impact energy absorbers: an overview,” Thin-Walled Structures 39 (2001) 189-213.

[28] Wadley, H.N.G., Fleck, N.A., Evans, A.G., "Fabrication and structural performance of periodic cellular metal sandwich structures," Composites Science and Technology 63 (2003) 2331-2343. 